\title{
Communication
}

\section{Apolar Annonaceous Acetogenins from the Fruit Pulp of Annona muricata}

\author{
Alice Melot ${ }^{1}$, Djibril Fall ${ }^{2}$, Christophe Gleye ${ }^{1}$ and Pierre Champy ${ }^{1, *}$ \\ 1 Laboratoire de Pharmacognosie, CNRS UMR 8076 BioCIS, Faculté de Pharmacie Paris-Sud 11, \\ Rue J. B. Clément, 92296 Châtenay-Malabry, France \\ 2 Laboratoire de Chimie Thérapeutique, Faculté de Pharmacie, Université Cheikh Anta Diop, Dakar, \\ Senegal; E-Mail: djibril_fall@yahoo.fr(D.F.)
}

* Author to whom correspondence should be addressed; E-Mail: pierre.champy@u-psud.fr; Tel.: +33-(0)146835639; Fax: +33-(0)146835399.

Received: 22 September 2009; in revised form: 19 October 2009 / Accepted: 22 October 2009 / Published: 2 November 2009

\begin{abstract}
A methylene chloride extract of the pulp of Annona muricata L. was fractionated in search for scarcely functionalized Annonaceous acetogenins (type E). Previously known C-35 and C-37 mono-epoxy unsaturated compounds, epomuricenins-A and $-\mathrm{B}(\mathbf{1}+\mathbf{2})$ and epomusenins-A and $-\mathrm{B}(3+4)$, were obtained. Two new mono-epoxy saturated C-35 representatives, epomurinins-A and $-\mathrm{B}(\mathbf{5 + 6})$ were also isolated.
\end{abstract}

Keywords: Annona muricata L.; annonaceae; annonaceous acetogenin

\section{Introduction}

Annona muricata L., a fruit tree growing in tropical and sub-tropical areas, is one of the main cultivated species of the genera, whose fruit is consumed either raw of after processing. This foodstuff is suspected of being implicated in the occurrence of atypical parkinsonian syndromes in the French West Indies [1, and see 2 in this issue]. The presence of Annonaceous acetogenins (ACGs) [3-5] of various polarities was assessed in the pulp, from which annonacin, the main neurotoxic candidate in the species, was isolated [6]. In the course of this chemical investigation, existence of precursors of THF-bearing ACGs (i.e., ACGs of type E) was suspected, but could not be ascertained, from observations with Kedde reagent-visualized thin layer chromatography (see Experimental section) or 
RP-HPLC-UV. MALDI-TOF MS (Matrix-Assisted Laser Desorption Ionization Time-of-Flight Mass Spectrometry), although successfully used as a new sensitive screening technique for ACGs, also proved unsuitable for a definitive identification of this particular group [2]. These ACGs generally exhibit moderate inhibition potential of mitochondrial complex I [3,7,8], and thus have doubtful significant neurotoxicity [9]. However, as Annonaceae fruit pulps have been largely understudied so far (fruit pulps were addressed in only $\sim 0.3 \%$ of peer-reviewed publications concerning ACGs!) [2], we pursued fractionation with a phytochemical and chemotaxonomic aim, focusing on these ACGs of weak polarity.

\section{Results and Discussion}

\section{Isolation and structural determination}

A classical purification process of a $\mathrm{CH}_{2} \mathrm{Cl}_{2}$ extract of lyophilized pulp, using consecutive Sephadex LH-20 ${ }^{\circledR}$ and silica gel open column chromatographies followed by preparative $\mathrm{C}_{18} \mathrm{RP}$ HPLC, allowed isolation of three white waxy solids $(\mathbf{1 + 2}, \mathbf{3 + 4}, \mathbf{5 + 6})$ from the apolar fractions. Each showed a single peak in analytical RP-HPLC, and reacted positively with Kedde reagent on thin layer chromatography.

Isolate 1+2 was obtained as a translucent waxy solid $(10 \mathrm{mg})$. Molecular mass was determined as 530 by CI-MS $\left([\mathrm{M}+\mathrm{H}]^{+}: m / z=531\right)$ leading to the molecular formula $\mathrm{C}_{35} \mathrm{H}_{62} \mathrm{O}_{3}$. The existence of an $\alpha, \beta$-unsaturated $\gamma$-lactone moiety, non hydroxylated at the C-4 position, was suggested by an IR carbonyl absorption at $1,750 \mathrm{~cm}^{-1}$ and UV $\lambda_{\max }$ at $209.2 \mathrm{~nm}$. It was confirmed by the ${ }^{1} \mathrm{H}-\mathrm{NMR}$ spectrum that showed seven protons at $\delta 7.00(\mathrm{H}-33, d), \delta 5.00(\mathrm{H}-34, q d), \delta 2.25(2 \mathrm{H}, \mathrm{H}-3, t)$ and $\delta$ $1.41 \mathrm{ppm}\left(\mathrm{CH}_{3}-35, d\right)$ which were correlated on ${ }^{1} \mathrm{H}-{ }^{13} \mathrm{C}$ correlation spectra (HSQC, HMBC) with carbon atoms at $\delta 148.0$ (C-33), 77.4 (C-34), $25.0(\mathrm{C}-3)$ and $19.2 \mathrm{ppm}\left(\mathrm{CH}_{3}-35\right)$, along with signals at $\delta 134.3(\mathrm{C}-2)$ and $173.9 \mathrm{ppm}(\mathrm{C}-1)$ (Figure 1).

Figure 1. NMR shifts for the lactonic moiety of $\mathbf{1}+\mathbf{2}$.

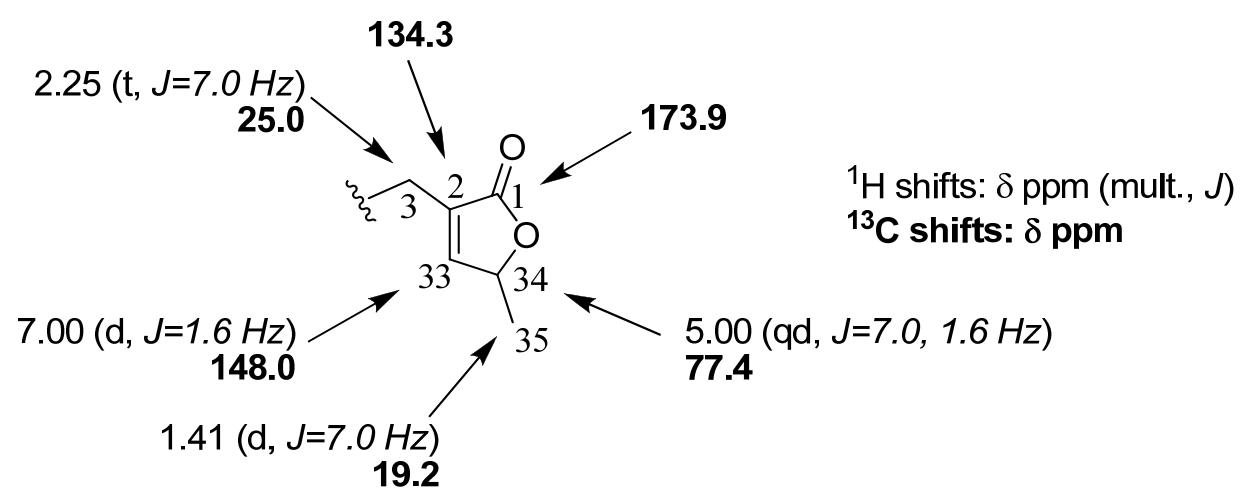

The presence of an epoxy ring was suggested by ${ }^{1} \mathrm{H}-\mathrm{NMR}$ resonances at $\delta 2.90$ and $2.93 \mathrm{ppm}$, each integrating for one proton $(\mathrm{H}-13 / \mathrm{H}-15, \mathrm{H}-14 / \mathrm{H}-16)$, correlating with carbon atoms at $\delta 56.8$ and $57.3 \mathrm{ppm}(\mathrm{C}-13 / \mathrm{C}-15, \mathrm{C}-14 / C-16)$. The presence of two multiplets at $\delta 5.39$ and $5.41 \mathrm{ppm}$, each integrating for one vinylic proton $(\mathrm{H}-17 / \mathrm{H}-19$ and $\mathrm{H}-18 / \mathrm{H}-20$, respectively) and correlating with signals at $\delta 128.1(\mathrm{C}-18 / C-20)$ and $\delta 130.8 \mathrm{ppm}(\mathrm{C}-17 / \mathrm{C}-19)$, revealed the existence of a double bond 
on the aliphatic chain. The comparison of NMR data with that of other double-bond containing acetogenins of known configuration [10-12] revealed a cis configuration (carbon allylic resonance value at $27.3 \mathrm{ppm}$, characteristic of a $Z$ relative configuration). The difference between the allylic methylenes ${ }^{13} \mathrm{C}$-NMR $\delta$ values suggested the proximity of the epoxy ring, which induces an upfield shift of the resonance of one of the two carbons ( $\delta$ 24.3/27.9 ppm). The ${ }^{1} \mathrm{H}-{ }^{1} \mathrm{H}$ COSY $\left(J^{l}\right)$ and HOHAHA $\left(J^{2}-J^{3}\right)$ spectra showed correlations between protons at $\delta 2.93(\mathrm{H}-14 / H-16), \delta 1.61(\mathrm{H}-15 / H$ 17), $\delta 2.22(\mathrm{H}-16 / H-18)$ and $\delta 5.39 \mathrm{ppm}(\mathrm{H}-17 / H-19)$, suggesting that the double bond and the epoxy ring are separated by two methylene units (Figure 2).

Figure 2. NMR shifts (a) and key ${ }^{1} \mathrm{H}^{1}{ }^{1} \mathrm{H}$ correlations (b) for the epoxy-ene system of $\mathbf{1}+\mathbf{2}$.
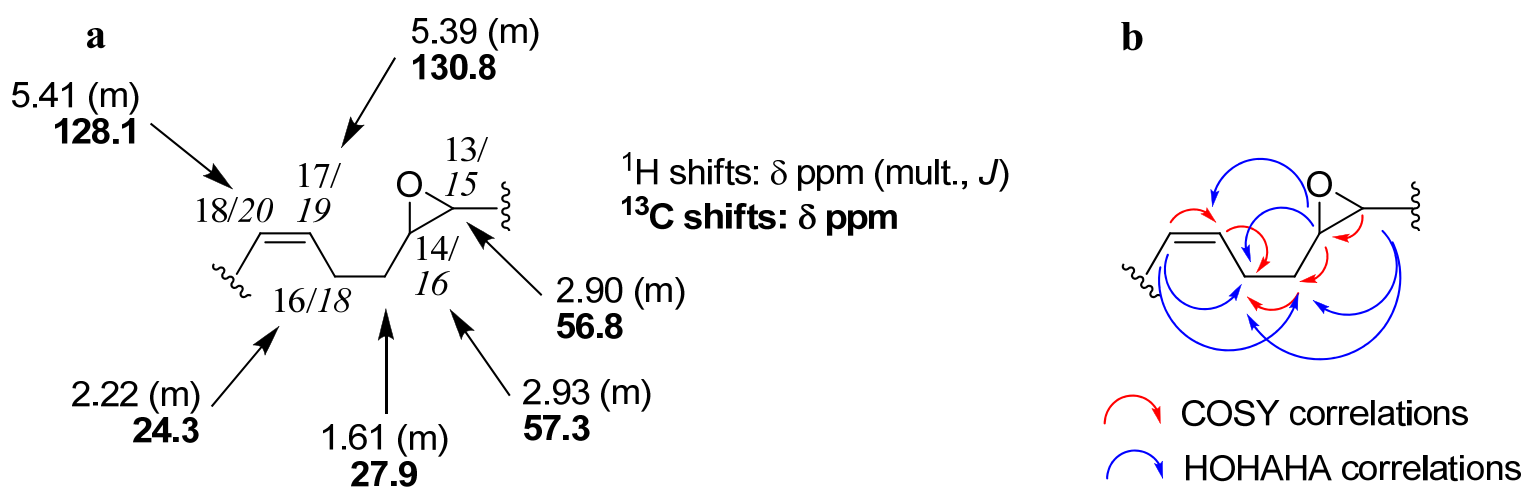

Two series of characteristic, intense fragments on the EIMS spectrum [3], at $m / z 321,308,307,295$ and at 293, 280, 279 and 267 suggested the existence of two isomers 1 and 2, allowing localization of epoxy ring at $C-15 / C-16$ or at $\mathrm{C}-13 / \mathrm{C}-14$, with the double bond location thus being $C-19 / C-20$ or $\mathrm{C}-17 / \mathrm{C}-18$, respectively. These compounds were identified, by comparison with spectral data from the literature, as being epomuricenin-A (1, epoxymurin-A) and epomuricenin-B (2), respectively (Figure 3) [12-14]. The same mixture had been previously obtained in our laboratory, from the seeds of the species $[10,12,13]$. Confirmation of the identity of $\mathbf{1 + 2}$ was obtained using RP-HPLC, by coinjection with an authentic sample. Comparison of the optical rotation for $\mathbf{1}+\mathbf{2}$ and the authentic sample suggested a $S$ stereochemistry at C-34. Epomuricenin-A and -B were first isolated as a mixture in the seeds of A. muricata [10]. Epomuricenin-A was also obtained from the bark of the species, under the name epoxymurin- $\mathrm{A}$, in a mixture with epoxymurin-B (epoxymurin-B bears an epoxide in positions C-17/C-18 and unsaturation in positions C-13/C-14) [14]. Characteristic EI-MS fragments of this last molecule were not observed, excluding its presence in the $\mathbf{1 + 2}$ mixture.

Isolate 3+4 (15 mg) was similarly identified as being a mixture, constituted of epomusenins-A (3) and -B (4) (Figure 3). Molecular mass was determined as 558 by CI-MS $\left([\mathrm{M}+\mathrm{H}]^{+}: m / z=559\right)$, corresponding to the molecular formula $\mathrm{C}_{37} \mathrm{H}_{66} \mathrm{O}_{3}$. 1D and 2D NMR data were quasi-identical to that of 1+2, suggesting an ACG bearing an unsaturated butyrolactone, no hydroxyl group, an epoxide and an olefinic group separated by two carbon atoms. The EI-MS spectrum provided evidence for the existence of the two isomers, and allowed location of the epoxide and therefore of the double bond respectively at $\mathrm{C}-17 / \mathrm{C}-18(\mathrm{~m} / \mathrm{z} 336,335,323)$ and $\mathrm{C}-21 / \mathrm{C}-22$ for epomusenin-A, and at C-15/C-16 $(\mathrm{m} / \mathrm{z} 308,307,295)$ and C-19/C-20 for epomusenin-B. These molecules had been previously isolated in our laboratory as a mixture from the roots of the plant [13]. Confirmation of the identity of $3+4$ was 
thus obtained by co-injection in RP-HPLC and by comparison of spectral data with that of the literature $[13,15]$. Optical rotation measurement suggested, as previously, a $S$-configuration for C-36. Epomusenins-A and -B were first described in the fruits of Rollinia mucosa [15].

Figure 3. Obtained ACGs: Epomuricenins-A (1, epoxymurin-A) and -B (2); Epomusenins$\mathrm{A}(3)$ and $-\mathrm{B}(4)$; Epomurinins-A (5) and -B (6).
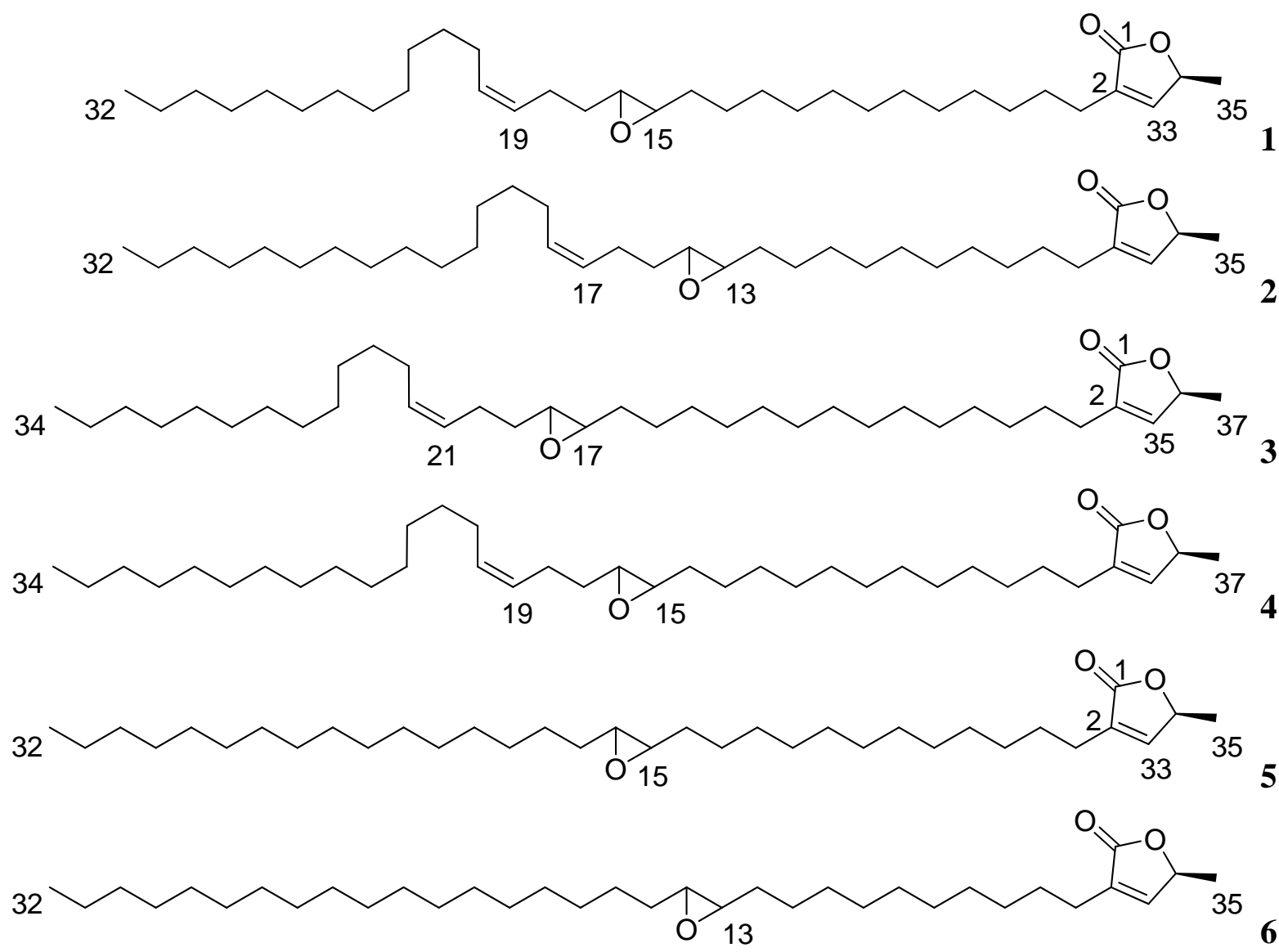

For isolate $5+6(2.5 \mathrm{mg})$, the CI-MS spectrum displayed a prominent peak at $\mathrm{m} / \mathrm{z}=533(100 \%$, $[\mathrm{M}+\mathrm{H}]^{+}$) leading to the molecular formula $\mathrm{C}_{35} \mathrm{H}_{64} \mathrm{O}_{3}$. The low amount of material obtained unfortunately did not allow acquisition of a clear ${ }^{13} \mathrm{C}$-NMR spectrum. However, similar ${ }^{1} \mathrm{H}-\mathrm{NMR}$ data (Table 1) as above showed for this ACG the presence of an $\alpha, \beta$-unsaturated $\gamma$-lactone moiety without a hydroxyl group at the $\mathrm{C}-4$ position and of an epoxy ring (multiplet integrating for two protons at $\delta 2.92 \mathrm{ppm}$ ). No ${ }^{1} \mathrm{H}-\mathrm{NMR}$ signals for a double bond could be observed, as suggested by the $2 \mathrm{amu}$ difference with epomuricenins-A and $-\mathrm{B}(\mathbf{1}+2)$. EI-MS showed $5+6$ to be a mixture, evidencing the presence of two compounds differing in the position of the epoxide group, at C-15/C-16 and at C13/C14 for 5 and 6, respectively (Figure 4). Compounds 5 and 6, which we named epomurinins-A and$\mathrm{B}$ are, to our knowledge, the first non-olefinic mono-epoxy ACGs described to date. They therefore are the first representatives of group 2b, in regard to the classification proposed by Bermejo et al. [4] in which group 2 (now proposed as group 2a) encloses mono-epoxy olefinic ACGs (type E-A) and group $\underline{3}$ comprises bis-epoxy ACGs (type E-B). In term of biogenetic relationships, no "naked" mono-ene ACG has been isolated to date. However, ACGs devoid of the THF moiety but bearing a threo vicinal diol, possibly arising from the opening of an isolated epoxy group, were described $[4,12]$. 
Table 1. ${ }^{1} \mathrm{H}-\mathrm{NMR}$ chemical shifts $(\delta \mathrm{ppm}, J \mathrm{~Hz})$ of ACGs $\mathbf{5}+\mathbf{6}$.

\begin{tabular}{|c|c|c|c|c|c|}
\hline Position (5) & Position (6) & $\delta_{\mathrm{H}}$, mult., $(J)$ & Position (5) & Position (6) & $\delta_{\mathrm{H}}$, mult., $(J)$ \\
\hline 3 & 3 & $2.26, \mathrm{t}(7.0)$ & 18 to 31 & 16 to 31 & $1.25-1.19, \mathrm{~m}$ \\
\hline 4 & 4 & $1.55, \mathrm{~m}$ & 32 & 32 & $0.87, \mathrm{t}(6.6)$ \\
\hline 5 to 13 & 5 to 11 & $1.25-1.29, \mathrm{~m}$ & 33 & 33 & $6.99, \mathrm{~d}(1.6)$ \\
\hline 14 & 12 & $1.32, \mathrm{~m}$ & 34 & 34 & $501 \mathrm{da}(70 \cdot 16)$ \\
\hline 15,16 & 13,14 & $2.92, \mathrm{~m}$ & & & \\
\hline 17 & 15 & $1.61, \mathrm{~m}$ & 35 & 35 & $1,41, \mathrm{~d}(7.0)$ \\
\hline
\end{tabular}

Figure 4. Key EI-MS fragmentation of ACGs (5+6).

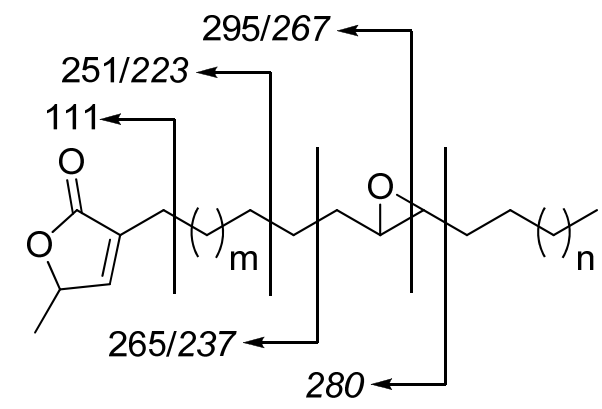

Epomurinin-A (5): $m=10, n=10$

Epomurinin-B (6): $m=8, n=12$

\section{Experimental}

\section{General}

Optical rotations were measured with a Schmidt-Haensch Polartronic I polarimeter. UV spectra were obtained in $\mathrm{MeOH}$ on a Philips PU 8720 spectrometer. IR spectra were recorded on a Bruker Vector 22 spectrometer. EI-MS spectra were recorded on an Automass multi (Thermo Finnigan, France), and CI-MS spectra with a Nermag-Sidar spectrometer. 1D and 2D NMR spectra were obtained with Bruker AC-200 (200 MHz) and Bruker AM-400 (400 MHz) spectrometers. TLC (thin layer chromatographies) were performed with Merck 60F254 silica plates and revealed with the Kedde reagent (dinitrobenzoic acid $10 \%$ in $\mathrm{MeOH}$, then $\mathrm{KOH} 2 \mathrm{~N}$ in $\mathrm{EtOH}$ ) for detection of unsaturated butyrolactones. For CC (column chromatography), Merck silica gels 60 (Merck 9385) and 60H (Merck 7736) and Sephadex ${ }^{\circledR}$ LH-20 (Pharmacia) were used (VWR, Fontenay sous Bois, France). RP-HPLC was performed with a Waters SSV injector, a Waters 590 pump, a Prepak $\mu$-Bondapak $\mathrm{C}_{18}$ column $(25 \times 100 \mathrm{~mm})$, a UV Waters 484 detector $(\lambda=214 \mathrm{~nm})$ and a ABB SE120 recorder (Waters Corporation, Milford, MA, USA and St. Quentin Falavier, France). Extraction solvents were purchased from Carlo-Erba (VWR) and HPLC grade $\mathrm{MeOH}$ from Prolabo. Water was purified by a Millipore water purification system and had a resistivity $>18 \mathrm{M} \Omega \cdot \mathrm{cm}^{-1}$. Authentic samples of ACGs where obtained by Dr C. Gleye $[12,13]$ in the course of previous studies.

\section{Plant material}

A. muricata L. fresh ripe fruits (soursop; $50 \mathrm{~kg}$ ) were purchased on a market in Dakar (Senegal). Seeds and pericarps were carefully removed and pulp was lyophilized (final mass: $1.4 \mathrm{~kg}$ ). 


\section{Extraction and isolation}

Pulp was extracted with $\mathrm{CH}_{2} \mathrm{Cl}_{2}$ in a Soxhlet apparatus (10 L, $\left.5 \mathrm{~d}\right)$. After solvent evaporation, an oily yellow residue, of strong and characteristic soursop odour, was obtained (14 g; yield: 1\%; $280 \mathrm{mg} / \mathrm{kg}$ of fresh fruit). $13 \mathrm{~g}$ of this extract were chromatographed on silica gel 60 (AcOEt $/ \mathrm{iPrOH}$ 9:1 $\rightarrow 1: 9)$ to give eight fractions (F1 to F8). Fraction F1 (4.5 g) was subjected to CC on Sephadex ${ }^{\circledR}$ LH-20 $\left(\mathrm{CH}_{2} \mathrm{Cl}_{2} / \mathrm{MeOH} 2: 1\right)$, yielding four fractions (F1-1 to F1-4). F1-1 was subjected to CC on silica gel $60 \mathrm{H}\left(\mathrm{C}_{6} \mathrm{H}_{12} / \mathrm{AcOEt} / \mathrm{iPrOH}\right.$ 13:0.3:0.3), yielding seven fractions (F1-1-1 to F1-1-7). Fractions F-11-4 (125 mg) and F-1-1-5 (103 mg) were merged and underwent CC on Sephadex ${ }^{\circledR}$ LH-20 $\left(\mathrm{CH}_{2} \mathrm{Cl}_{2} / \mathrm{MeOH}\right.$ 2:1), yielding four fractions (F-1-1-4/5-1 to F-1-1-4/5-4). F-1-1-4/5-4 (84 mg) was fractionated by RP-HPLC $\left(\mathrm{MeOH} / \mathrm{H}_{2} \mathrm{O}\right.$ 9:1, flow: $\left.10 \mathrm{~mL} / \mathrm{min}\right)$ to yield three single peak fractions of sufficient mass to allow spectroscopic analysis: $\mathbf{1}+\mathbf{2}(10 \mathrm{mg}, \mathrm{Rt}=22 \mathrm{~min}), \mathbf{3}+\mathbf{4}(15 \mathrm{mg}$, $\mathrm{Rt}=34 \mathrm{~min})$ and $\mathbf{5}+\mathbf{6}(2.5 \mathrm{mg}, \mathrm{Rt}=10 \mathrm{~min})$.

\section{Spectral data}

Epomuricenins $-A$ and $-B(\mathbf{1}+2)$ : White wax, $[\alpha]_{\mathrm{D}}=+8^{\circ}\left(\mathrm{c} 0.015, \mathrm{CHCl}_{3}\right)$; IR: 2,900, 2,830, 1,750, 1,460, 1,310, 1,200, 1,110, 1,060, 1,010 cm $\mathrm{cm}^{-1} \mathrm{UV}(\mathrm{MeOH}) \lambda_{\max }(\log \varepsilon): 209.2$ (3.60); CI-MS $\left(\mathrm{CH}_{4}\right)$ : $m / z=531\left[\mathrm{C}_{35} \mathrm{H}_{62} \mathrm{O}_{3}+\mathrm{H}\right]^{+}(100 \%), 531,513,111 ;$ EI-MS $(40 \mathrm{eV}): m / z=\underline{321}, \underline{293}, \underline{307}, \underline{308}, \underline{295}, \underline{280}$, $\underline{279}, \underline{267}, \underline{251}, 237, \underline{223}, 209,195,181,167,153,139,125, \underline{111} ;{ }^{1} \mathrm{H}-\mathrm{NMR}\left[\mathrm{CDCl}_{3}, 300 \mathrm{MHz}, \delta(\mathrm{ppm})\right.$, $J(\mathrm{~Hz})]: \delta 0.88(3 \mathrm{H}, t, J=7.0, \mathrm{H}-32), 1.25-1.29(36 \mathrm{H}, m, \mathrm{H}-5-\mathrm{H}-11 / H-5-H-13, \mathrm{H}-21-\mathrm{H}-31 / H-$ 23-H-31), 1.32 (2H, $m, \mathrm{H}-12 / H-14), 1.41(3 \mathrm{H}, d, J=7.0, \mathrm{H}-35), 1.50$ (2H, $m, \mathrm{H}-20 / H-22), 1.55$ (2H, $m, \mathrm{H}-4), 1.61$ (2H, $m, \mathrm{H}-15 / H-17), 2.05$ (2H, $m, \mathrm{H}-19 / H-21), 2.22(2 \mathrm{H}, m, \mathrm{H}-16 / H-18), 2.25$ (2H, $t, J=$ 7.0, H-3), $2.90(1 \mathrm{H}, m, \mathrm{H}-13 / H-15), 2.93(1 \mathrm{H}, m, \mathrm{H}-14 / H-16), 5.00(1 \mathrm{H}, q d, J=7.0$ and 1.6, H-34), $5.39(1 \mathrm{H}, m, \mathrm{H}-17 / \mathrm{H}-19), 5.41(1 \mathrm{H}, m, \mathrm{H}-18 / \mathrm{H}-20), 7.00(1 \mathrm{H}, d, J=1.6, \mathrm{H}-33) .{ }^{13} \mathrm{C}-\mathrm{NMR}\left(\mathrm{CDCl}_{3}, 200\right.$ MHz): 14.1 (C-32), 19.2 (C-35), 22.5 (C-31), 24.3 (C-16/C-18), 25.0 (C-3), 26.6-29.7 (C-22-C-29/C24-C-29), 27.0 (C-4), 27.3 (C-19/C-21), 27.5-30.0 (C-5-C-12/C-5-C-14), 27.9 (C-15/C-17), 32.0 (C-30), $56.8\left(\mathrm{C}-13 * / C-15^{*}\right), 57.3\left(\mathrm{C}-14 * / C-16^{*}\right), 77.4$ (C-34), 128.1 (C-18/C-20), 130.8 (C-17/C-19), 134.3 (C-2), 148.0 (C-33), 173.9 (C-1) (epomuricenin-B / epomuricenin-A) (*: interchangeable).

Epomusenins- $A$ and $-B(3+4)$ : White wax, $[\alpha]_{\mathrm{D}}=+9^{\circ}\left(\mathrm{c} 0.015, \mathrm{CHCl}_{3}\right)$; IR (film): 2,903, 2,835, 1,742, 1,463, 1,311, 1,213, 1,109, 1,050, 1,013 cm $\mathrm{cm}^{-1}$ UV (MeOH) $\lambda_{\max }(\log \varepsilon): 208.6$ (3.72); CI-MS $\left(\mathrm{CH}_{4}\right)$ : $m / z=559\left[\mathrm{C}_{37} \mathrm{H}_{66} \mathrm{O}_{3}+\mathrm{H}\right]^{+}(100 \%), 559,541,336,312,270,130,95 ;$ EI-MS $(40 \mathrm{eV}): m / z=\underline{336}, \underline{323}$, $307, \underline{308}, \underline{295}, 279,265,251,237,223,209,195,181,167,153,139,125,111 ;{ }^{1} \mathrm{H}-\mathrm{NMR}\left[\mathrm{CDCl}_{3}, 300\right.$ $\mathrm{MHz}, \delta(\mathrm{ppm}), J(\mathrm{~Hz})]: \delta 0.88(3 \mathrm{H}, t, J=6.7, \mathrm{H}-34), 1.25-1.29(40 \mathrm{H}, m, \mathrm{H}-5-\mathrm{H}-13 / H-5-H-15, \mathrm{H}-$ 23-H-33/H-25-H-33), 1.32 (2H, $m, \mathrm{H}-22 / H-24), 1.50$ (2H, $m, \mathrm{H}-14 / H-16), 1.41(3 \mathrm{H}, d, J=7.0, \mathrm{H}-$ 37), 1.50 (2H, $m, \mathrm{H}-23 / H-25), 1.55$ (2H, $m, \mathrm{H}-4), 1.58$ (2H, $m, \mathrm{H}-17 / H-19), 2.05$ (2H, $m, \mathrm{H}-21 / H-23)$, $2.22(2 \mathrm{H}, m, \mathrm{H}-18 / \mathrm{H}-20), 2.25$ (2H, $t, \mathrm{~J}=7.1, \mathrm{H}-3), 2.91(1 \mathrm{H}, m, \mathrm{H}-15 / H-17), 2.93(1 \mathrm{H}, m, \mathrm{H}-16 / H-$ 18), $5.00(1 \mathrm{H}, q d, J=6.8$ and 1.5, H-36), $5.39(1 \mathrm{H}, m, \mathrm{H}-19 / \mathrm{H}-21), 5.41(1 \mathrm{H}, m, \mathrm{H}-20 / H-22), 7.00$ $(1 \mathrm{H}, d, J=1.5, \mathrm{H}-35) .{ }^{13} \mathrm{C}-\mathrm{NMR}\left(\mathrm{CDCl}_{3}, 200 \mathrm{MHz}\right): 14.1(\mathrm{C}-34), 19.2(\mathrm{C}-37), 22.5(\mathrm{C}-31), 24.3(\mathrm{C}-$ 16/C-18), 25.2 (C-3), 26.6-29.7 (C-5-C-13/C-5-C-15, C-24-C-31/C-26-C-31), 27.4 (C-4, C-17/C19, C-19/C-21), 27.7 (C-14/C-16), 32.0 (C-32), 56.7 (C-15*/C-17*), 57.0 (C-16*/C-18*), 77.4 (C-36), 128.0 (C-20/C-22), 131.0 (C-19/C-21), 134.2 (C-2), 148.0 (C-35), 173.9 (C-1) (epomusenin-B/ 
epomusenin-A) (*: interchangeable). Key COSY and HOHAHA correlations between protons at $\delta$ : $2.93,1.61,2.22,5.41 \mathrm{ppm}$ allowed relative positioning of epoxy and olefinic groups at a distance of two carbon atoms.

Epomurinins- $A$ and $-B(5+6)$ : White wax, $[\alpha]_{\mathrm{D}}=+5^{\circ}\left(\mathrm{c} 0.0015, \mathrm{CHCl}_{3}\right)$; IR: $2,902,2,835,1,748,1,460$, 1,311, 1,212, 1,110, 1,050, 1,012 $\mathrm{cm}^{-1}$; UV (MeOH) $\lambda_{\max }: 209.2 ;$ CI-MS $\left(\mathrm{CH}_{4}\right): \mathrm{m} / z=533$ $\left[\mathrm{C}_{35} \mathrm{H}_{62} \mathrm{O}_{3}+\mathrm{H}\right]^{+}(100 \%), 531,513,111$; EI-MS (40 eV): $\mathrm{m} / z=321,293,307,308,295,280,279,267$, 251, 237, 223, 209, 195, 181, 167, 153, 139, 125, 111 (see Figure 2; epomuricenin-A/epomuriceninB); ${ }^{1} \mathrm{H}-\mathrm{NMR}\left(\mathrm{CDCl}_{3}, 300 \mathrm{MHz}\right)$ : see Table 1 . Comparison of $[\alpha]_{\mathrm{D}}$ with that of $\mathbf{1}+\mathbf{2}, \mathbf{3}+\mathbf{4}$ and of related compounds [12,13] suggests an $S$ configuration for C-34. However, absolute configurations for C13/C-14/C-15/C-16 remain ambiguous; Mixtures of epimers for 5 and 6 can be suspected [16], this uncertainty remaining for the majority of epoxy-ACGs [4].

\section{Conclusion}

Isolation of type E Annonaceous acetogenins $\mathbf{1}$ to $\mathbf{6}$ offers a new insight into chemical composition of the fruit of Annona muricata, in relation to its probable role in the occurrence of sporadic atypical Parkinsonism in tropical areas. This result also suggests that fruit pulp might be a place for biosynthesis of ACGs and for their "maturation" into THF-bearing representatives such as annonacin. Epomurinins-A (5) and-B (6), the first "naked" mono-epoxy ACGs (proposed as group 2b ACGs), are minor compounds. Biogenesis of type-A (mono-THF) ACGs is proposed to result from oxygenation steps from dienic representatives [3,17]. In the hypothesis that ACGs 5 and $\mathbf{6}$ are not end-products, they might be precursors of several THF-bearing ACGs. To undergo such a fate, $\mathbf{5}$ and $\mathbf{6}$ would require further reduction ( $\rightarrow$ group $2 \mathrm{a}$ - type E-A), epoxidation ( $\rightarrow$ group 3 - type E-B) then hydratation steps, yielding type A ACGs (Figure 5) [3,17, and see 12]. Occurrence of these compounds would therefore illustrate the apparently poorly specific sequential distribution of biosynthetic steps $[17,18]$ towards biologically efficient ACGs [3,4].

Figure 5. Putative pathway from group $2 \mathrm{~b}$ to type A ACGs.

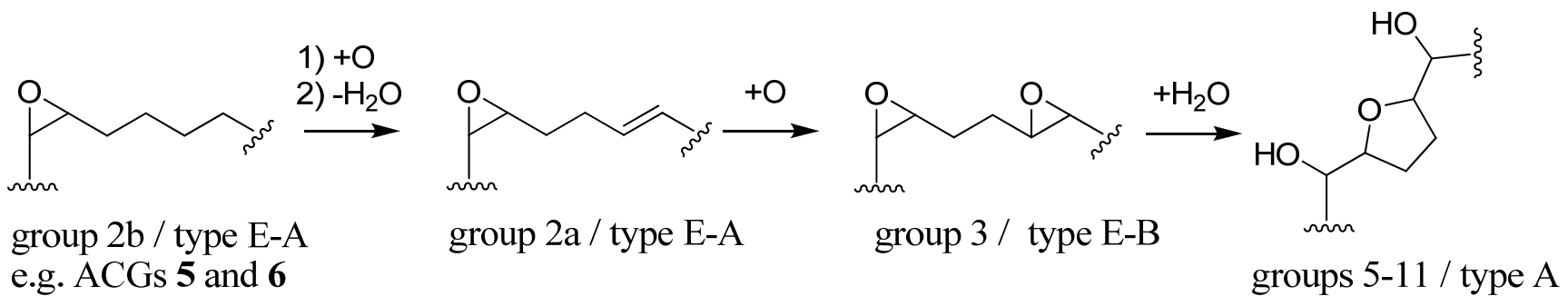

\section{Abbreviations}

ACG: Annonaceous acetogenin; amu: atomic mass unit; $\mathrm{CC}$ : column chromatography; CI: chemical ionization; EI: electronic impact; MS: mass spectrometry; NMR: nuclear magnetic resonance; RPHPLC: reversed-phase high performance liquid chromatography; TLC: thin layer chromatography. 


\section{Acknowledgements}

The authors wish to thank Pr. A. Laurens and Pr. R. Hocquemiller for their participation in this study, B. Figadère and Pr. E. Poupon for re-reading and constructive criticism of the manuscript, J.C. Julian for NMR measurements, the staff of the Service d'Analyse des Métabolites et des Médicaments for MS experiments. Financial support was provided by the Centre National de la Recherche Scientifique.

\section{References and Notes}

1. Höglinger, G.U.; Michel, P.P.; Champy, P.; Féger, J.; Hirsch, E.C.; Ruberg, M.; Lannuzel, A. Experimental evidence for a toxic etiology of tropical parkinsonism. Mov. Disord. 2005, 20, $118-119$.

2. Champy, P; Guérineau, V.; Laprévote, O. MALDI-TOF MS profiling of Annonaceous acetogenins in Annona muricata products of human consumption. Submitted, 2009.

3. Cavé, A.; Figadère, B.; Laurens, A.; Cortes, D. Acetogenins from Annonaceae. In: Progress in the Chemistry of Organic Natural Products. Herz, W., Kirby, G.W., Moore, R.E., Steglich, W., Tamm, C., Eds.; Springer: New York, NY, USA, 1997; pp. 81-288.

4. Bermejo, A.; Figadère, B.; Zafra-Polo, M.C.; Barrachina, I.; Estornell, E.; Cortes, D. Acetogenins from annonceae: Recent progress in isolation, synthesis and mechanisms of action. Nat. Prod. Rep. 2005, 22, 269-303.

5. McLaughlin, J.L. Paw Paw and Cancer: Annonaceous acetogenins from discovery to commercial products. J. Nat. Prod. 2008, 71, 1311-1321.

6. Champy, P.; Melot, A.; Guérineau, V.; Gleye, C.; Höglinger, G.U.; Ruberg, M.; Lannuzel, A.; Laprévote, O.; Laurens, A.; Hocquemiller, R. Quantification of acetogenins in Annona muricata linked to atypical parkinsonism in Guadeloupe. Mov. Disord. 2005, 20, 1629-1633.

7. Abe, M.; Kenmochi, A.; Ichimaru, N.; Hamada, T.; Nishioka, T.; Miyoshi, H. Essential structural features of acetogenins: role of hydroxy groups adjacent to the bis-THF rings. Bioorg. Med. Chem. Lett. 2004, 14, 779-782.

8. Konno, H.; Hiura, N.; Makabe, H.; Abe, M.; Miyoshi, H. Synthesis and mitochondrial complex I inhibition of dihydroxy-cohibin A, non-THF Annonaceous acetogenin analogue. Bioorg. Med. Chem. Lett. 2004, 14, 629-632.

9. Höllerhage, M.; Matusch, A.; Champy, P.; Lombès, A.; Ruberg, M.; Oertel, W.H.; Höglinger, G.U. Natural lipophilic inhibitors of mitochondrial complex I are candidate toxins for sporadic tau pathologies. Exp. Neurol. 2009, in press.

10. Roblot, F.; Laugel, T.; Lebœuf, M.; Cavé, A.; Laprévote O. Two acetogenins from Annona muricata seeds. Phytochemistry 1993, 34, 281-285.

11. Zeng, L.; Zhang, Y.; McLaughlin, J.L. Gigantransenin A, B, and C, novel mono-THF acetogenins bearing trans double bonds from Goniothalamus giganteus (Annonaceae). Tetrahedron Lett. 1996, 37, 5449-5452.

12. Gleye, C.; Laurens, A.; Hocquemiller, R.; Laprévote, O.; Serani, L.; Cavé, A. Cohibins A and B, acetogenins isolated from roots of Annona muricata L. Phytochemistry 1997, 44, 1541-1545. 
13. Gleye, C. Acétogénines des racines et des graines d'Annona muricata (Annonaceae): Etude particulière des précurseurs biogénétiques. PhD Thesis. Université Paris-Sud 11: Paris, France, 1998.

14. Hisham, A.; Sreekala, U.; Pieters, L.; De Bruyne, T.; Van den Heuvel, H.; Claeys, M. Epoxymurins $\mathrm{A}$ and B, two biogenetic precursors of Annonaceous acetogenins from Annona muricata. Tetrahedron 1993, 49, 6913-6920.

15. Chen, Y.Y; Chang, F.R.; Yen, H.F.; Wu, Y.C. Epomusenins A and B, two acetogenins from fruits of Rollinia mucosa. Phytochemistry 1996, 42, 1081-1083.

16. Hu, Y.; Cecil, A.R.L.; Franck, X.; Gleye, C.; Figadère, B.; Brown, R.C.D. Natural cis-solamin is a mixture of tetraepimeric diastereoisomers: Biosynthetic implications for Annonaceous acetogenins. Org. Biomol. Chem. 2006, 4, 1217-1219.

17. Gleye, C.; Laurens, A.; Laprévote, O.; Serani, L.; Hocquemiller, R. Isolation and structure elucidation of sabadelin, an acetogenin from roots of Annona muricata. Phytochemistry 1999, 52, 1403-1408.

18. Bajin ba Ndob, I.; Champy, P.; Gleye, C.; Lewin, G.; Akendengué, B. Annonaceous acetogenins: Precursors from the seeds of Annona squamosa. Phytochemistry Lett. 2009, 2, 72-76.

Sample Availability: Samples of the compounds $\mathbf{1 + 2}$ and $\mathbf{3}+\mathbf{4}$ are available from the authors.

(C) 2009 by the authors; licensee Molecular Diversity Preservation International, Basel, Switzerland. This article is an open-access article distributed under the terms and conditions of the Creative Commons Attribution license (http://creativecommons.org/licenses/by/3.0/). 